تقييم منظومة دعم الخبز الجديدة في محافظة بني سويف

حسين محمد أحمد رستم و عبد العظيم سيد عبد العظيم عبد اللطيف

معهر بحوث تكنولوجيا الأغذية - مركز البحوث الزراعية - جيزة - مصر

(المستخلص

يُعتبر الإستقرار الإجتماعي والإقتصادي أحد المحاور الرئيسية لضمان مستوي معيشة آمن لأفراد المجتمع، وتسعي حكومات الدول الإنمادي المختلفة المتقدمة والنامية علي السواء إلي تحقيق حد أدني مناسب لمستوي معيشة لهنة

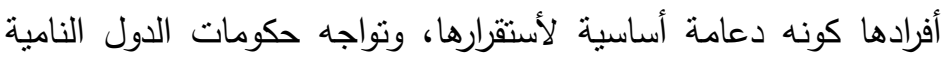
تحديات كبيرة لتحقيق هذا الأمر في ظل مواردها المالية المحدودة.

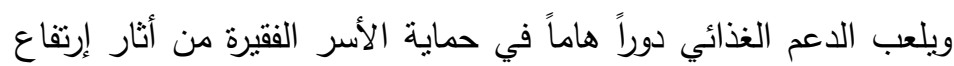

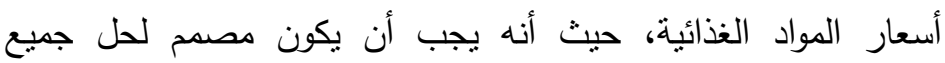

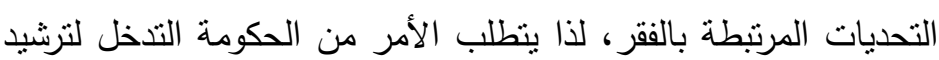
الدعم بما يعمل علي توجيه الدعم إلي مستحقية الفعليين وبصورة جيدة وفي الوقت المناسب لذلك. وكفاءة الدعم تعمل علي توفير في الميزانية

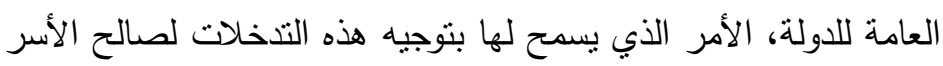

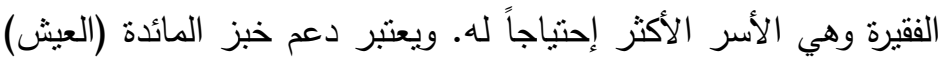

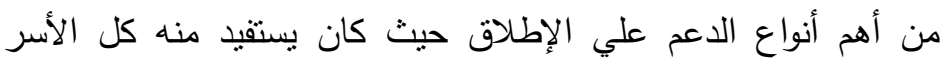

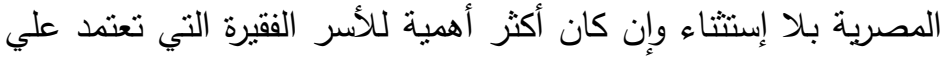
الخبز بصفة أساسية في وجباتها الغذائية اليومية. إن رفع كفاءة منظومة دعم خبز المائدة بصفة خاصة سوف يكون له مردود إجنماعي وإقتصادي وسياسي عالي حيث يضمن تحقيق عدالة إجتماعية في التوزيع، تضمن لكل فرد نصيبه من خبز المائدة، ينعكس عليه بالأمن والطمأنينه، وصدق رسول الله صلي الله عليه وسلم حيث قال في الحديث

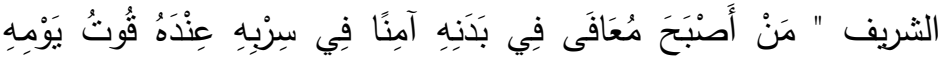

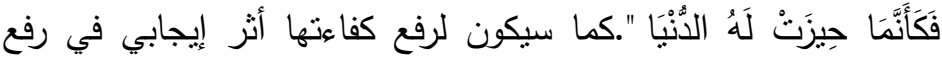

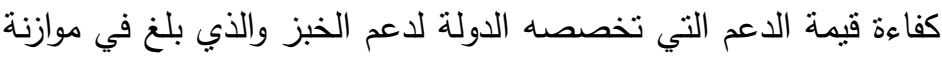

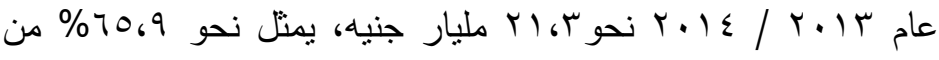

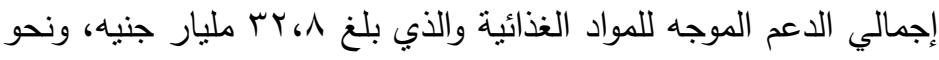

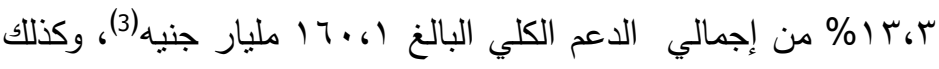
أثز إيجابي في تقليل الفاقد في خبز المائدة. مشكلة البحث 
:تتمثل مشكلة البحث في عدم وجود أي أبحاث أودراسات نوضح مدي نجاح منظومة الخبز الجديدة في

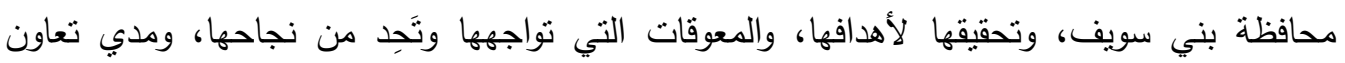
الجهات العاملة في تتفيذ المنظومة من عدمه.

\section{أهدف البحث}

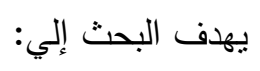

ا ـ التعرف علي الوضع الراهن لتطبيق منظومة الخبز الجديدة في محافظتبني سويف. r. تقييم مدي نجاح المنظومة في تحقيق أهدافها، والتي من أهمها تحقيق العدالة الإجتماعية لونية ووصول الدعم إلي مستحقيه، وتيسير حصول المواطنين علي خبز المائدة، والقضاء علي ظاهرة طوابير شراء الخبز أمام المخابز، وعلاج مشكلة تهريب الدقيق الددعم للسوق السوداء، وتقليل الفاقد من خبز المائدة.

r. رصد المعوقات والمشاكل التي تحد من نجاح المنظومة وخفض كفاءتها. ع. تقديم الحلول والمقترحات التي من شأنها أن تساعد صانع القرار في نطوير وتحسين ونسين جودة

\section{المنظومة.}

أسلوب البحث ومصادر الحصول علي البيانات:إعتمد البحث لتحقيق أهدافه علي الأساليب العلمية في

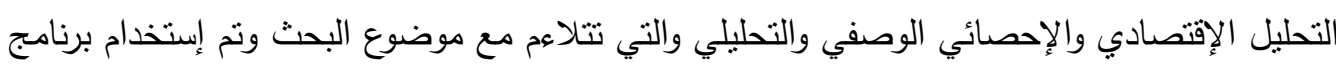

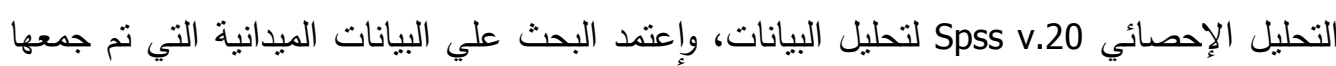

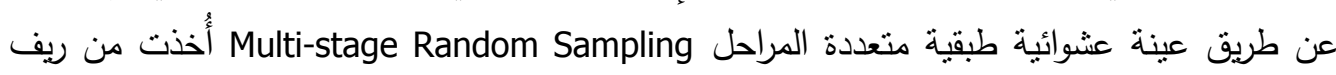
وحضر محافظة بني سويف وذللك خلال شهري مارس وإبريل من عام 10 . ب، من خلال إستمارة

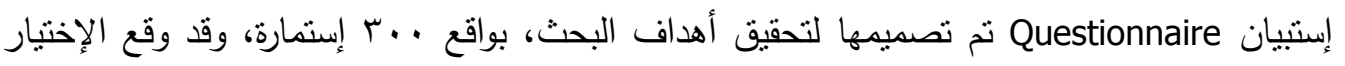

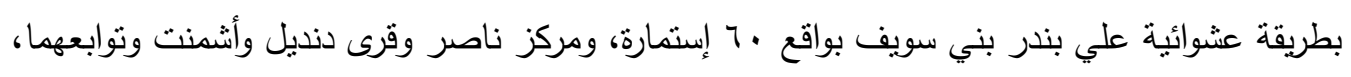

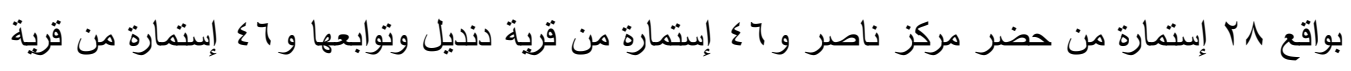

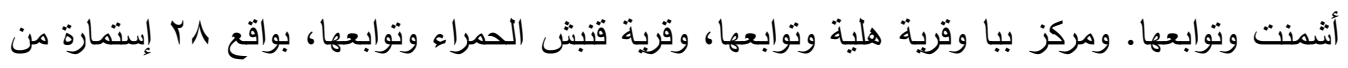

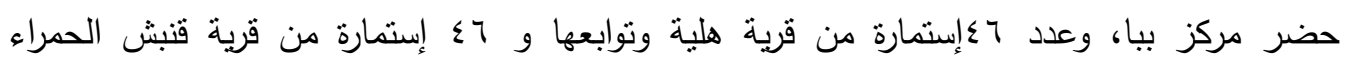

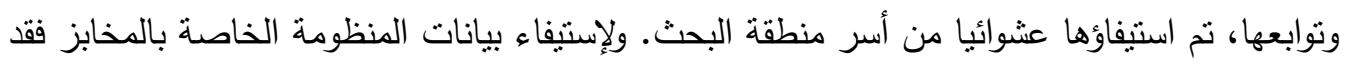

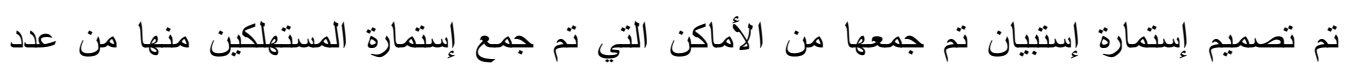

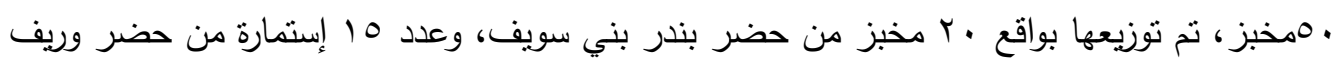
مركز ناصر ، وكذلك عدد 10 مخبز من حضر وريف مركز ببا. أما بالنسبة للمطاحن فقد نم تصميم

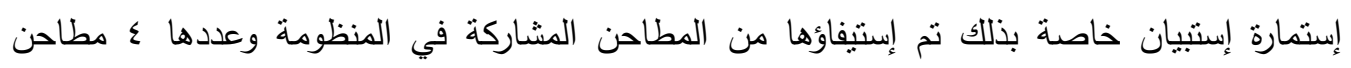

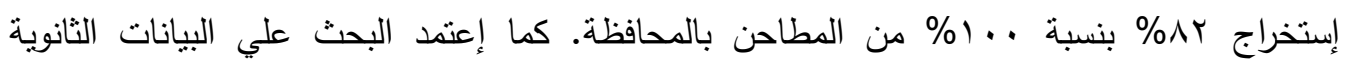

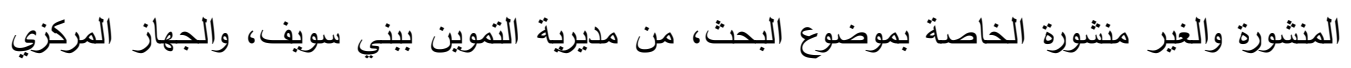
للتعبئة العامة والإحصاء. 
خصائص ومكونات منظومة الخبز الجديدة ببني سويف: تبين من نتائج البحث أن تطبيق منظومة الخبز الجديدة في بني سويف بداء في شهر سبتمبر عـا.با، وبلغ عدد الذين شملتهم

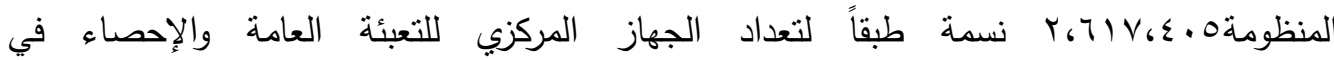

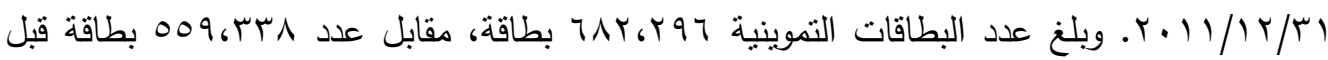

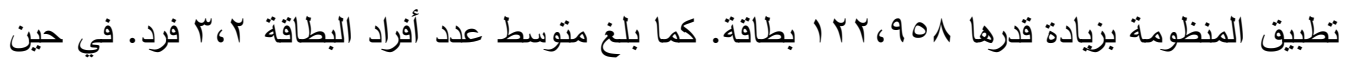

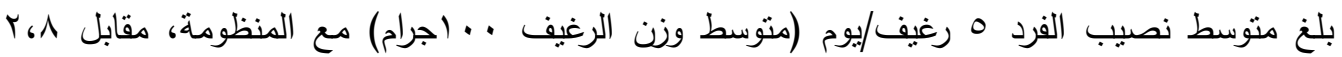

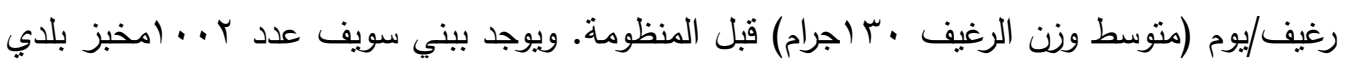

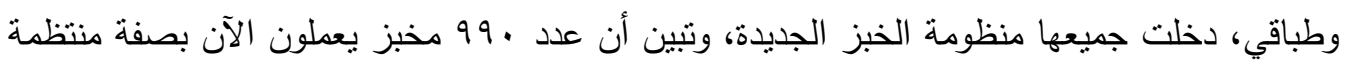

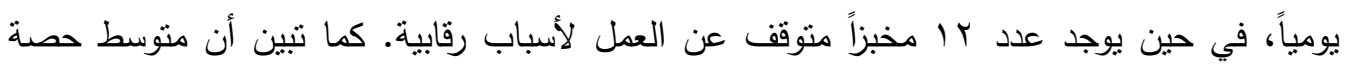
(كثافة) المخبز من عدد السكان ب آب فردم/يوم، وبلغ متوسط حصة المحافظة من الدقيق إستخلاص

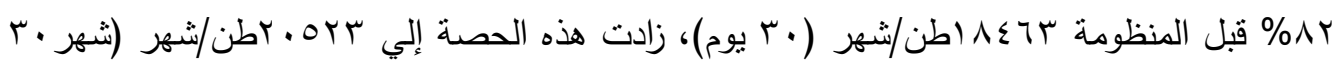

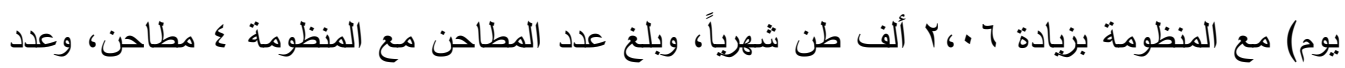

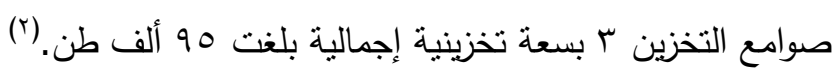

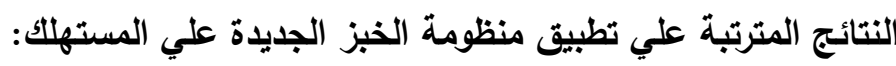

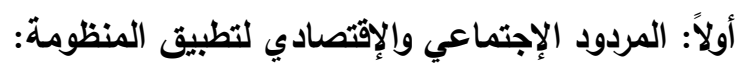
أ:رضا المستهلكين عن منظومة الخبز الجديدة وجودة الخبز الناتج:تبين من نتائج البحث أن إجمالي

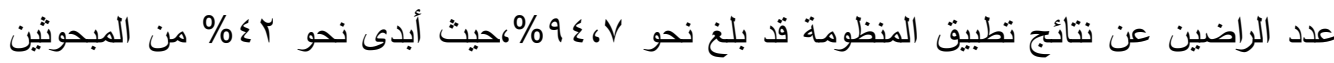

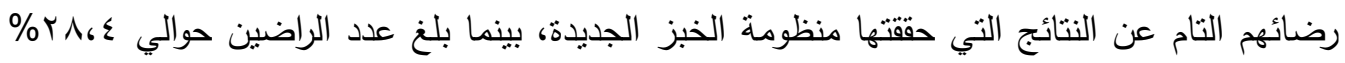

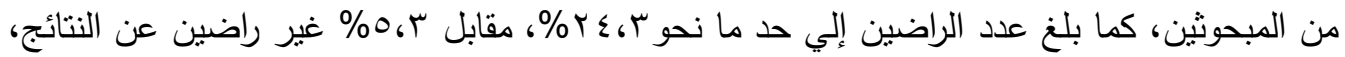

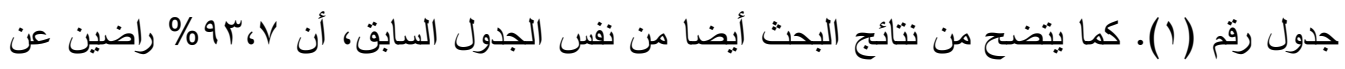

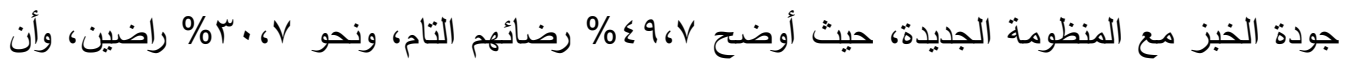

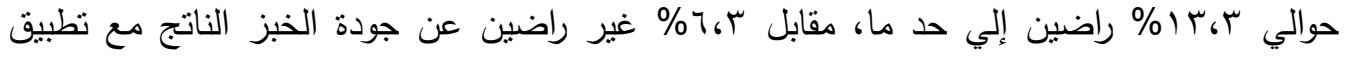
المنظومة الجديدة. 
جدول رقم (1) : رضا المستهلكين عن منظومة الخبز الجديدة وجودة الخبز الناتج بعد تطبيق المنظومة.

\begin{tabular}{|c|c|c|}
\hline$\%$ & عدد & 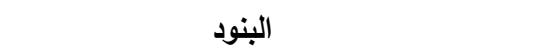 \\
\hline & & رضا المستهلكين عن المنظومة الجديدة: \\
\hline$\varepsilon r$ & Ir4 & راضي تماما \\
\hline r^، $\varepsilon$ & 10 & 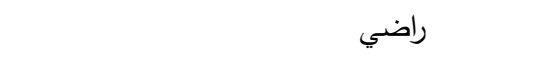 \\
\hline$r \leq r$ & vV & راضي إلي حد ما \\
\hline$r$ & 7 & غير راضي إلي حد ما \\
\hline r.r & 1. & غير راضي \\
\hline $1 \cdots$ & r.. & الإجمالي \\
\hline & & رضا المستهلكين عن جودة الخبز مع المنظومة: \\
\hline$\varepsilon 9 . v$ & $1 \leqslant 9$ & راضي تماما \\
\hline$r \cdot \sigma v$ & 94 & 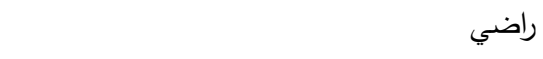 \\
\hline Ir.r & $\varepsilon$ & راضي إلي حد ما \\
\hline $7, r$ & 19 & غير راضي \\
\hline $1 \ldots$ & r.. & إجمالي عينة البحث \\
\hline
\end{tabular}

المصدر : جمعت وحسبت من بيانات إستمارة الإستبيان.

بد:دور المنظومة في توفير الإحتياجات اليومية للأسرة من الخبز وطرق توفئن الأنير العجز منها

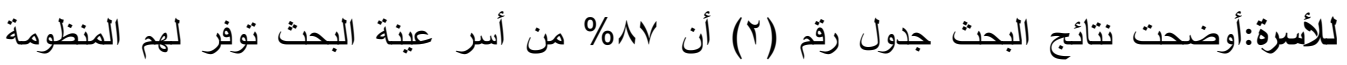

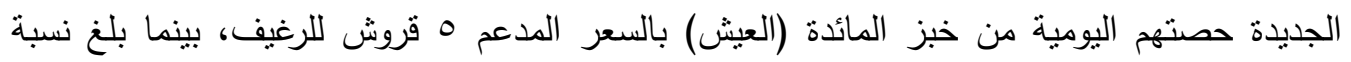

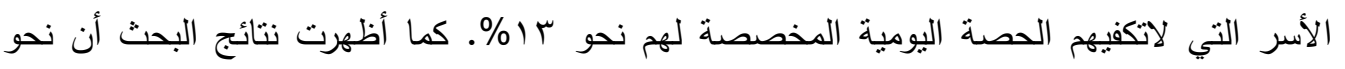

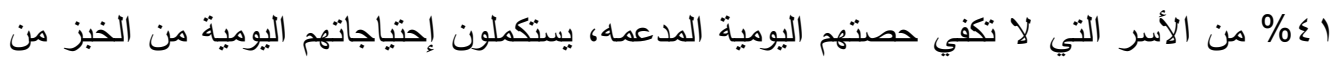

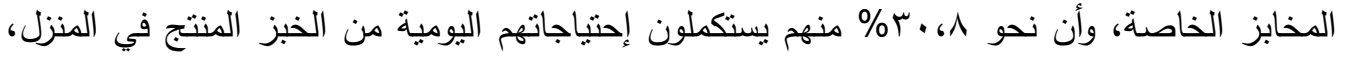

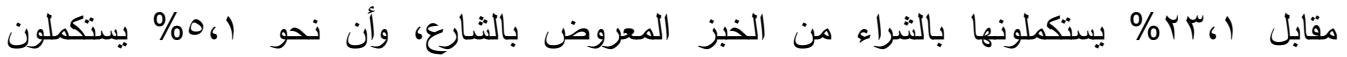
إحتياجاتهم اليومية عن طريق شرائها من مخابز المنظومة بالسعر الحر مب قرش للرغيف. جدول رقم(ץ): الأهمية النسبية لمدى كفاية الحصة اليومية للقرد ومصادر سد العجز اليومي من الخبز.

\begin{tabular}{|c|c|c|}
\hline$\%$ & العدد & البنود \\
\hline & & 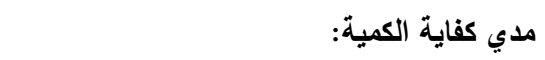 \\
\hline$\Lambda V$ & YT) & تكفي \\
\hline Ir & rq & 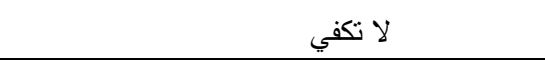 \\
\hline & & مصدر إستكمال النقص من الإحتياجات اليومية: \\
\hline$\varepsilon$ & 17 & 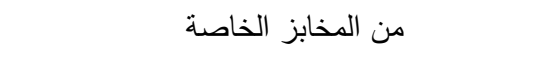 \\
\hline r. A & ir & من البيت \\
\hline$r r_{6}$ & 9 & 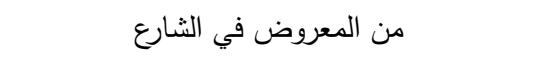 \\
\hline 0,1 & r & من المخابز البلدية \\
\hline
\end{tabular}

المصدر : جمعت وحسبت من بيانات إستمارة الإستبيان. 
ج: المنظومة ودورها في خفض إنفاق الأسرة الشهري علي خبز المائدة:أظهرت نتائج البحث أن تطبيق منظومة الخبز الجديدة بمحافظة بني سويف كان له نتائج إقتصادية هامة علي الأسرة تنثلت في

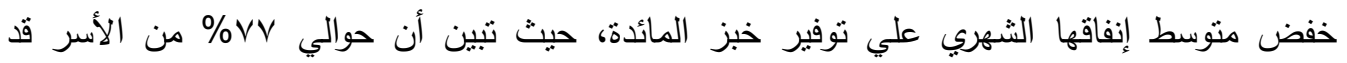

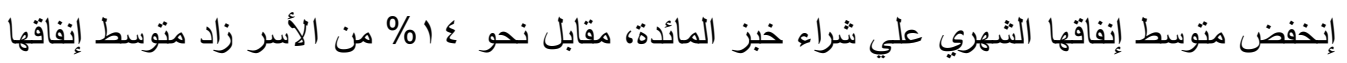

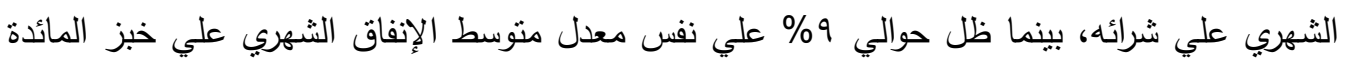
جدول رقم (r). كما بينت نتائج البحث أن أسباب إنخفاض متوسط إنفاق الأسرة الثهري علي شراء

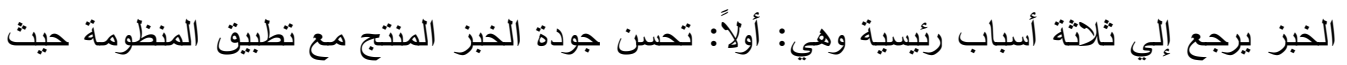
أثنار نحو ع، ـ00\% من المستهلكين بذلك. ثانياً:توفير المنظومة وضمانها للحصة اليومة التي يحتاجها

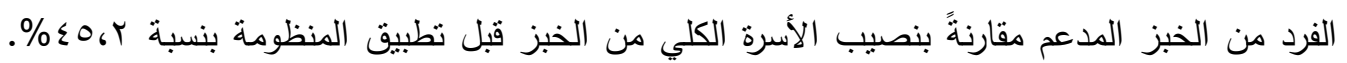
ثالثاً: حصول الأسر علي سلع غذائية نتيجة توفيرها لنقاط رصيد الخبز تساعد في الغذاء اليومي للأسرة

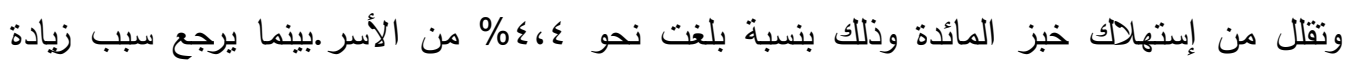

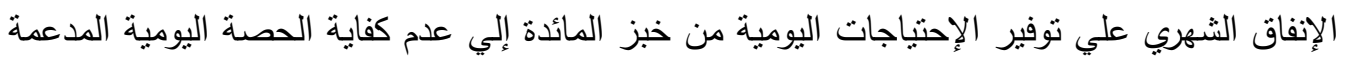
للأسرة وإستكمالها من السوق بالسعر الحر ، ويتزكز ذلك في الأسر الفقيرة التي تعتمد علي خبز المائدة

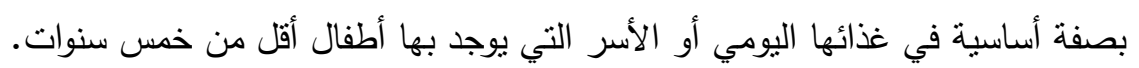
جدول رقم(r): أثر المنظومة علي حجم إنفاق الأسرة الثهري علي الخبز وأسباب إنخفاضه أو زيادته.

\begin{tabular}{|c|c|c|}
\hline الأهمية النسبية & العدد & 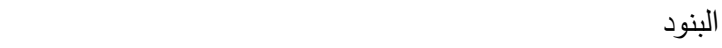 \\
\hline & & مستوي الإنفاق: \\
\hline$V V$ & וTr & 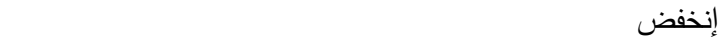 \\
\hline $1 \leq$ & $\leqslant r$ & زاد \\
\hline 9 & rV & 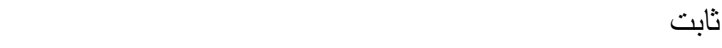 \\
\hline & & أسباب إنخفاض الإنفاق الثهري: \\
\hline $0 . ، \varepsilon$ & 1ra & تحسن جودة الخبز المُدعم \\
\hline$\sum 0,4$ & Irt & الحصول علي الإحتياج الكلي للأسرة من الخبز المدعم \\
\hline$\varepsilon$ ، & it & توفر سلع غذائية مدعمه من رصيد الخبز تساعد في الغذاء اليومي \\
\hline & & أسباب زيادة الإنفاق الشهري علي الخبز \\
\hline $1 \cdots$ & $\varepsilon r$ & عدم كفاية الخبز المدعم وشراء الإحتياجات من السوق الحرة. \\
\hline
\end{tabular}

المصدر : جمعت وحسبت من بيانات إستمارة الإنتبيان.

د: تطبيق منظومة الخبز الجديدة ودورها في تقليل فاقد خبز المائدة:نبين من نتائج البحث جدول رقات رقم

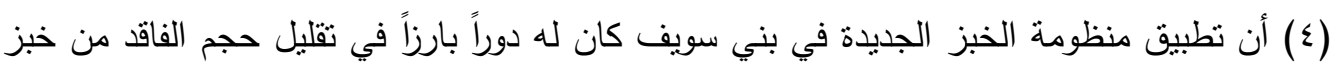

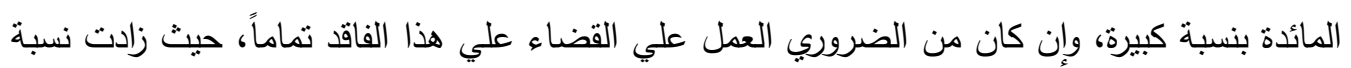

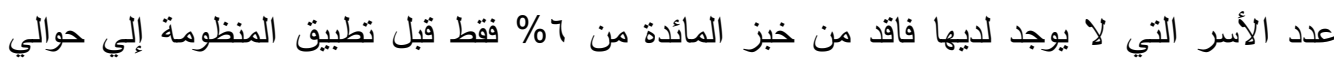

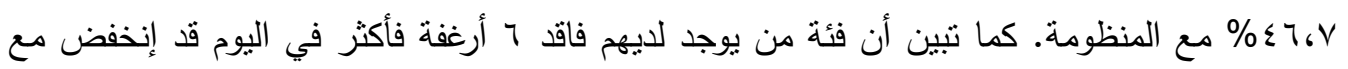

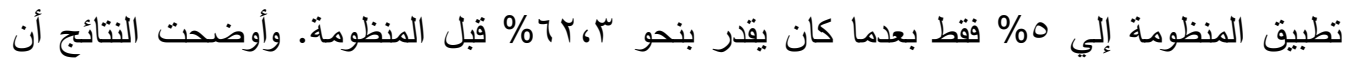

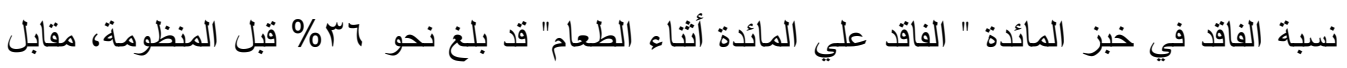




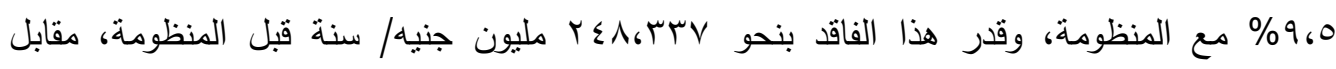

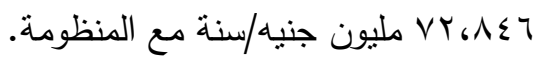
خامسا:نقاط الخبز وأسباب عدم توفير بعض الأسر لها:يمنل رصيد التوفير (نقاط الخبز) نقلة أساسية

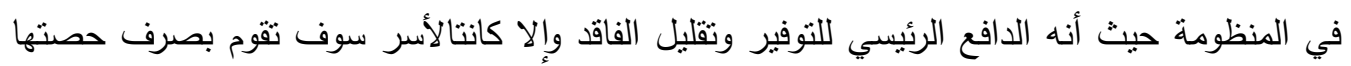

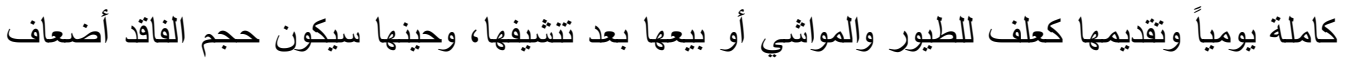

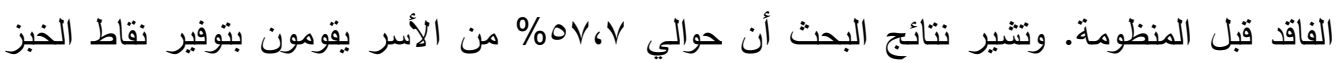

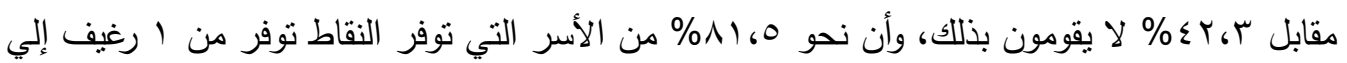

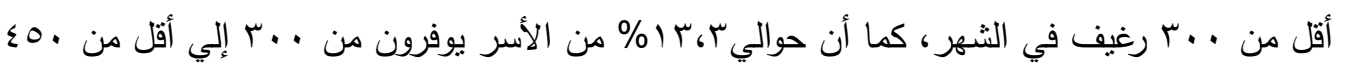

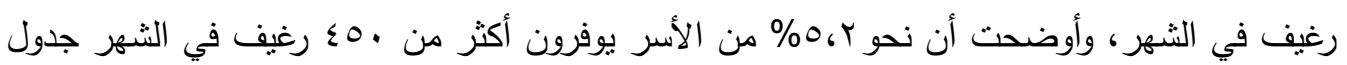
رقم (0). وفيما يتعلق جدول رقم (ع ): فاقد خبز المائدة وأثر تطبيق المنظومة عليه.

\begin{tabular}{|c|c|c|c|c|c|c|c|c|}
\hline \multicolumn{2}{|c|}{ ج أرغفة فأكثر } & \multicolumn{2}{|c|}{ من ץ لأقل من ج رغيف } & \multicolumn{2}{|c|}{ من الأقل من سررغيف } & \multicolumn{2}{|c|}{ لا يوجد فاقد } & \multirow{2}{*}{ البنود } \\
\hline$\%$ & عدد & $\%$ & عدد & $\%$ & عدد ع & $\%$ & عدد & \\
\hline 0 & 10 & $r \cdot \sigma r$ & 71 & $r \wedge$ & 10 & $\leqslant 7, V$ & $1 \leq$. & مع المنظومة \\
\hline ש, Tד & $1 \wedge V$ & ro & vo & $7 . \mathrm{V}$ & $r$. & 7 & 11 & قبل المنظومة \\
\hline
\end{tabular}

كمية الفاقد بالرغيف وقيمته بالمليون جنيه

\begin{tabular}{|c|c|c|c|c|c|c|}
\hline \multicolumn{3}{|c|}{ مع المنظومة } & \multicolumn{3}{|c|}{ قبل المنظومة } & \multirow[b]{2}{*}{ البنود البن } \\
\hline قيمة الفاقد ** & كمية الفاقد * & الفاقد & قيمة الفاقد ** & كمية الفاقد* & \% الفاقد & \\
\hline$\vee Y_{6} \wedge \leq 7$ & A.r & 9,0 & $r \varepsilon \Lambda_{6} r r V$ & $1, .1 r_{6} T 1 \Lambda_{6} V_{\ldots}$ & די & الفاقد \\
\hline
\end{tabular}

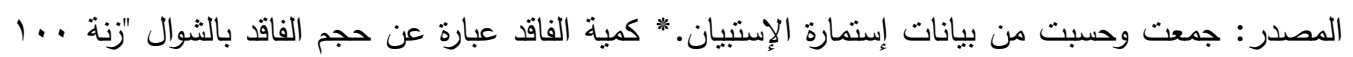

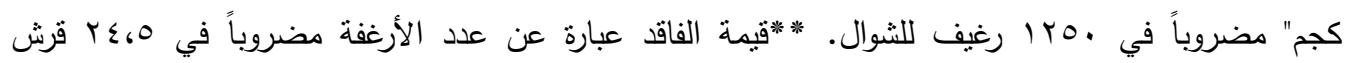
للرغيف.

أسباب عدم توفير بعض الأسر لنقاط الخبز ، فقد أظهرت نتائج البحث أن ع، ، ـ \% يرجعون السبب إلي

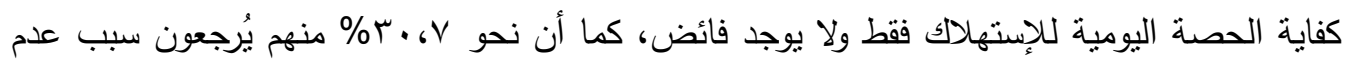

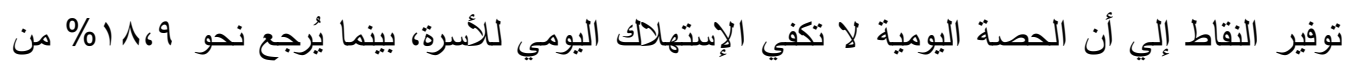
الأسر عدم التوفير إلي قيام الموزعين "خاصة في القرى والنجوع والعزب" بجمع البطاقات من الأفراد

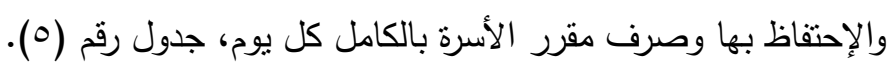


جدول رقم (ه): فئات توفير رصيد الخبز (نقاط الخبز) وأسباب عدم توفير بعض الأسر له.

\begin{tabular}{|c|c|c|}
\hline الأهمية النسبية النية & 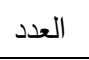 & 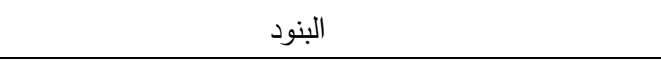 \\
\hline & & 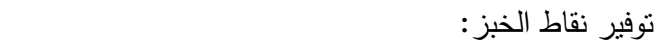 \\
\hline ov, & lVr & 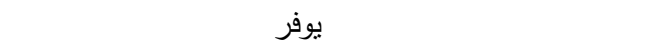 \\
\hline$\varepsilon r_{6} T^{2}$ & irV & ل ل ايوفر \\
\hline & & فئات توفير رصيد الخبز : \\
\hline 11,0 & $1 \leqslant 1$ & من I : أقل من . .ب رغيف \\
\hline ir.r & r & 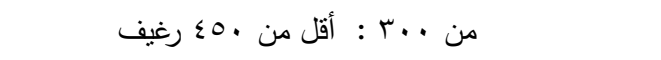 \\
\hline $0, r$ & 9 & أكثر من .0 0؛ رغيف \\
\hline $1 \ldots$ & ivr & إجمالي أسر التوفير \\
\hline & & أسباب عدم التوفير : \\
\hline $0 . ، \varepsilon$ & $7 \varepsilon$ & الحصة تكفي الاستهلاك اليومي فقط \\
\hline$r \cdot \sigma v$ & rq & الحصة لا تكفي \\
\hline 11,9 & $r \varepsilon$ & جمع الموزعين للبطاقات وصرف الحصة كاملة يومياً \\
\hline $1 \ldots$ & irt & الإجمالي لأسباب عدم التوفير \\
\hline
\end{tabular}

المصدر : جمعت وحسبت من بيانات إستمارة الإستنيان.

ثانياً:إيجابيات تطبيق منظومة الخبز الجديدة في بني سويف:أظهرت نتائج البحث إلي تحقيق منظومة

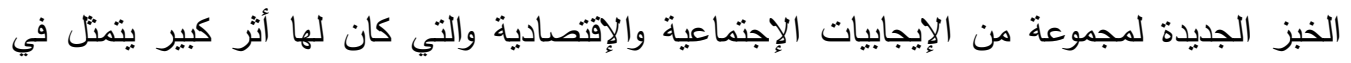

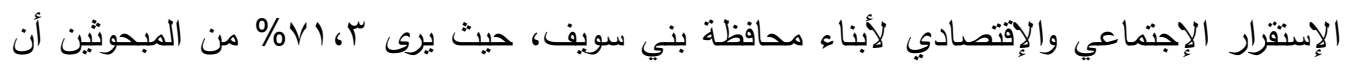
منظومة الخبز عملت علي تحقيق العدالة في توزيع الخبز المدعم وتحقيق الرضا الإجنماعي من خلاد لإلئل

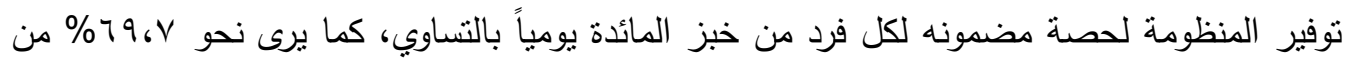

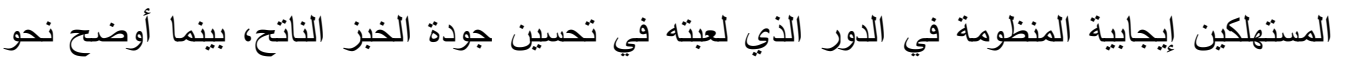
\%०9،V V أن للمنظومة الفضل في تيسير وسهولة حصول المستهلكين علي الخبز اليومي وإختفاء

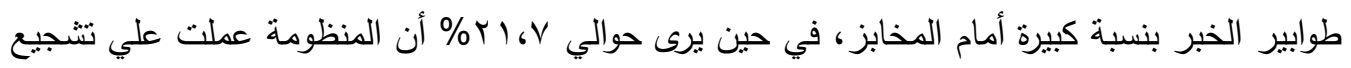

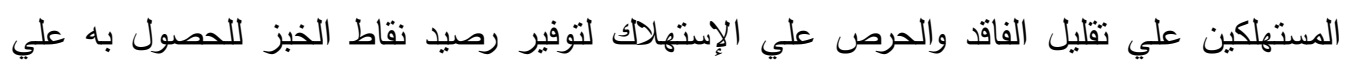
السلع التموينية الأخري الضرورية للأسرة مثل الزيت والأرز والعدس والسكر وغيرها من السلع الغذائية الضرورية للأسرة. كما أوضحت نتائج البحث أن المنظومة دفعت أصحاب المخابز إلي العمل علي الصني

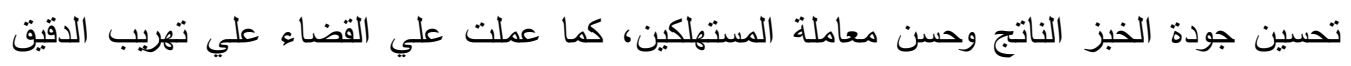

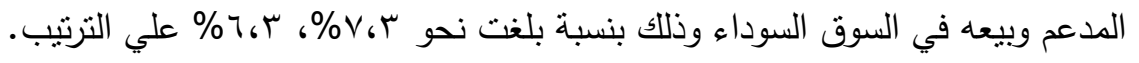


جدول رقم (†) : إيجابيات تطبيق منظومة الخبز الجديدة في بني سويف.

\begin{tabular}{|c|c|c|}
\hline الأهمية النسبية النية & العدد & إيجابيات تطبيق منطومة الخبز الجديدة \\
\hline$v 1, r$ & Y! & تحقيق العدالة والرضا الإجتماعي في التوزيع وضمان حصة عيش جيدة للفرد \\
\hline 79.7 & $r \cdot 9$ & 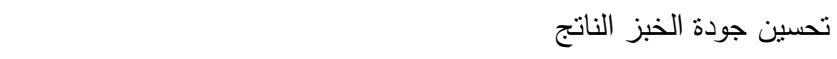 \\
\hline $096 \mathrm{~V}$ & $1 \times 9$ & تيسير وسهولة حصول المواطن علي الخبز وإختفاء الطوابير أمام المخابز \\
\hline r), & 70 & شجعت الأفراد علي تقليل الفاقد لتوفير رصبد الخبز لشراء السلع الاخري به \\
\hline$v_{6} r$ & rr & 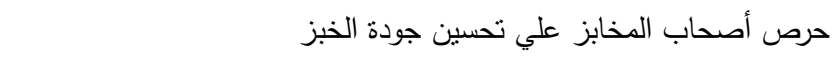 \\
\hline 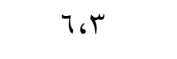 & r. & القضاء علي تهريب الدقيق الدعم إلي السوق السوداء \\
\hline r.7 & 11 & مرونة وحق المواطن من صرف حصته من أي مخبز بالمحافظة \\
\hline $1 \ldots$ & r.. & إجمالي عينة البحث \\
\hline
\end{tabular}

المصدر : جمعت وحسبت من بيانات إستمارة الإنتبيان.

ثالثاً: المعوقات التي تواجه تطبيق منظومة الخبز الجديدة وتقلّل من نجاحها:

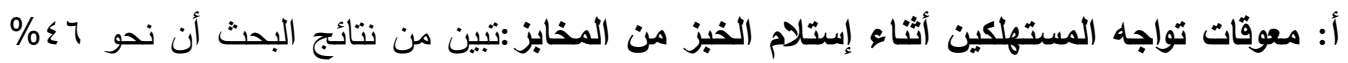

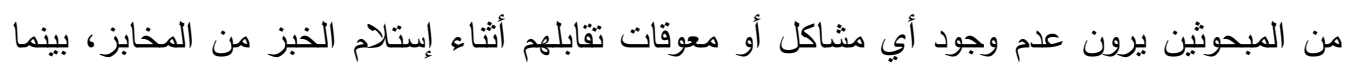

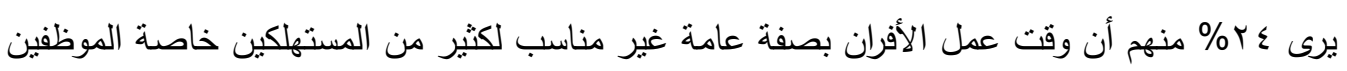
حيث لا يستطيعون شراء الخبز صباحاً لإنشغالهم بالذهاب إلي مقر أعمالهم مبكراً، وفي أخر اليوم

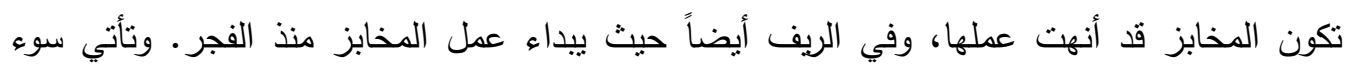

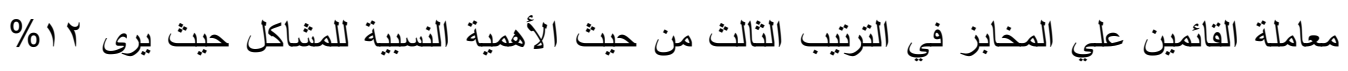

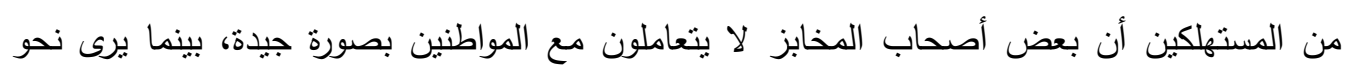

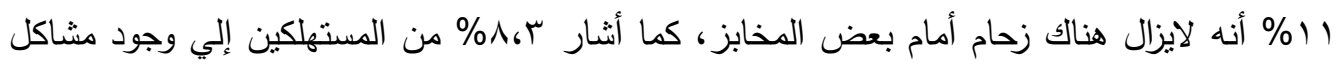

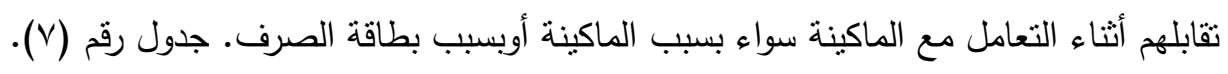
ب: مشاكل ومعوقات عامة تواجه نجاح المنظومة: أوضحت نتائج البحث أن من أهم المعوقات التي لته تواجه أو تحد من نجاح المنظومة في بني سويف هو عدم كفاية ممثلى للجهات الرقابية وعدم القيام

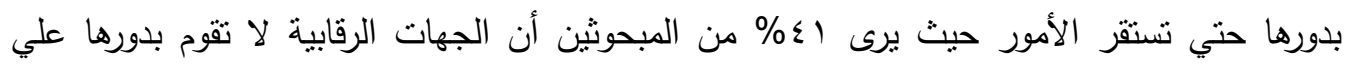

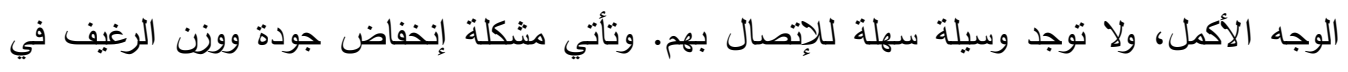

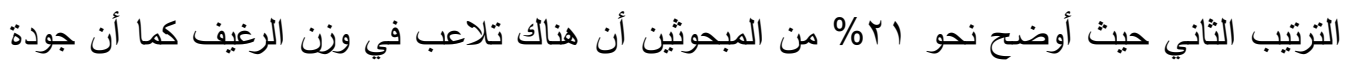

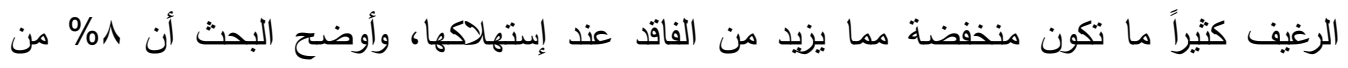
المواطنين يشتكون من قيام بعض أصحاب المخابز بإفتعال المشكلات والمعوقات لخلق حالة من الزحام أمام المخبز كي يضطر المستهلكين إلي شراء الخبز بأي وضع من الجودة، خاصة في في الأماكن التي

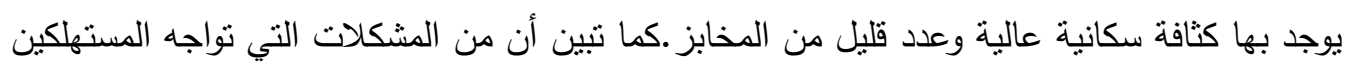

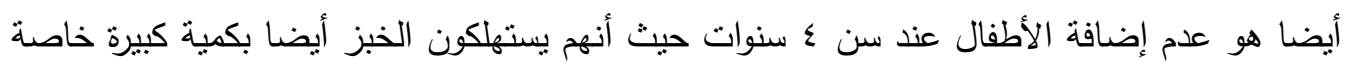
في الأسر الفقيرة، وكذلك عدم كفاية الحصة اليومية للأسر الفقيرة حيث بلغت نسبة كل كل منهما

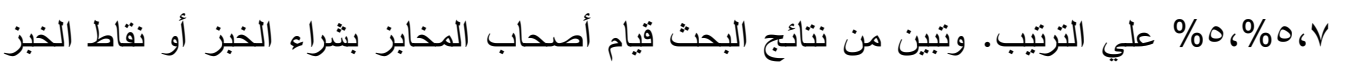

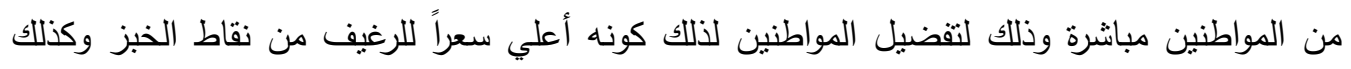
يحصل عليه فوري من صاحب المخبز حيث منلت هذه النسبة نحو ب\% ممن شملتهم عينة البحث. كما 
تأتي مشكلة تلاعب مفتشي التموين بالكارت الذهبي وعدم إستخدامه في الغرض المخصص له حيث

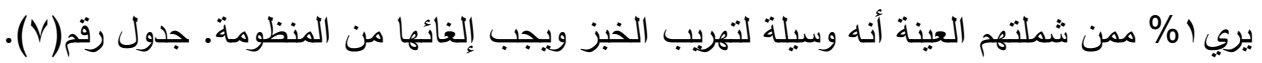

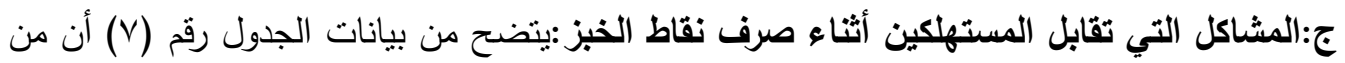

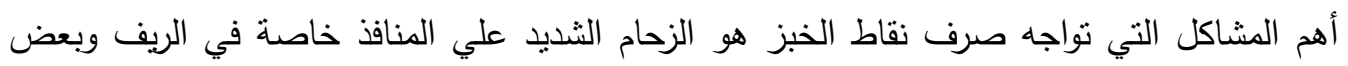

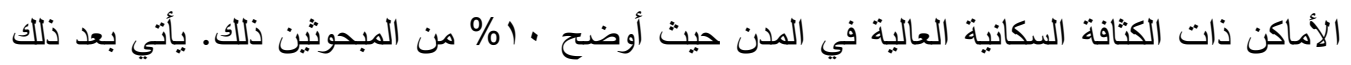

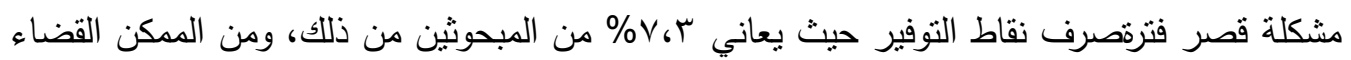

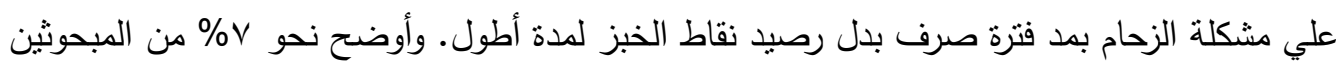

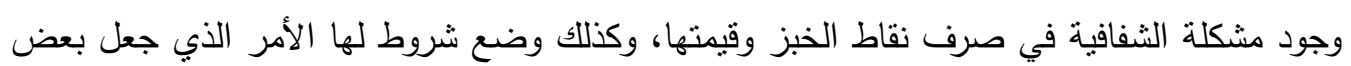

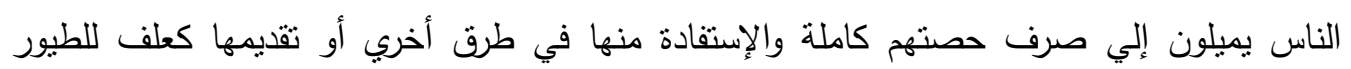

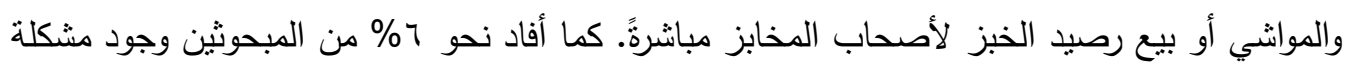

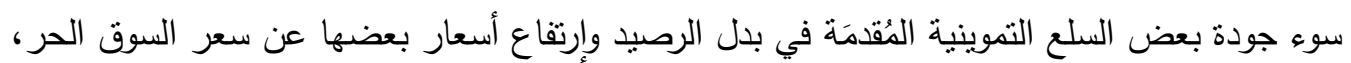
ويُرجِع أصحاب منافذ نوزيع السلع التموينية ذلك إلي تكلفة النقل والإكراميات التي يتحملونها عند إستلام

$$
\text { السلع ونقلها من المؤسسات. }
$$

عدم جدول رقم (V) المشاكل والمعوقات التي تواجه المنظومة وتقلل من تحقيقها لأهدافها كاملة.

\begin{tabular}{|c|c|c|}
\hline الأهمية النسبية & العدد & 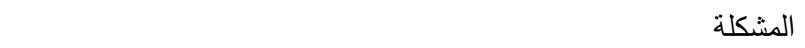 \\
\hline & & ا ا:مشاكل نواجه المستهلكين أثناء إستلام الخبز من المخابز \\
\hline $0 \leqslant$ & 174 & لاتوجد مشاكل أثناء الشراء \\
\hline$r \varepsilon$ & VY & عدم مناسبة وقت عمل المخابز مع الموظفين وأصحاب الأعمال \\
\hline it & Tr & 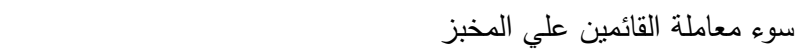 \\
\hline 11 & r & وجود زحمة أمام المخبز \\
\hline$\Lambda_{6} \mathrm{r}$ & ro & مشاكل الماكينة أو الكارت \\
\hline & & 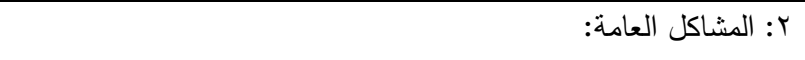 \\
\hline$\varepsilon 1$ & rra & غياب الجهات الرقابية أثناء مختلف مراحل المنظومة خاصة المخابز \\
\hline r) & זיד & إنخفاض جودة ووزن الرغيف في أوقات كثيرة \\
\hline$\wedge$ & $r \varepsilon$ & إفتعال أصحاب المخابز لمشاكل لصنع زحام وإضطرار الناس للشراء \\
\hline $0, \mathrm{~V}$ & iv & 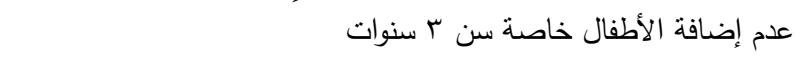 \\
\hline$\circ$ & 10 & عدد الأرغفة غير كاف للأسر الفقيرة \\
\hline r & 9 & بيع المواطنين رصيد الخبز لأصحاب المخابز \\
\hline 1 & r & تلاعب مفتش التموين بالكارت الذهبي وصرفه كاملا مع أصحاب المخابز \\
\hline 1. & r. & rالزحام الثديد نتيجة قلة التي تقابل المستهلكين أثناء صرف المنافذ التي تقوم بعملية الصرف رصبد الخبز : \\
\hline$v_{6} r$ & rr & قصر فترة السماح الخاصة بصرف رصيد توفير الخبز (نقاط الخبز) \\
\hline v & r) & عدم وجود شفافية في صرف رصيد التوفير ووضع شروط لصرفه \\
\hline 1 & 11 & سوء جودة بعض السلع وإرتفاع سعرها بحجة مصاريف الإستلام والنقل \\
\hline r. & $\wedge$ & تأخر وعدم ونوفر بعض السلع خاصة الزيت \\
\hline- & $r \ldots$ & إجمالي عينة البحث \\
\hline
\end{tabular}

المصدر : جمعت وحسبت من بيانات إستمارة الإستبيان.

رابعأ: مقترحات تحسين أداء منظومة الخبز ببني سويف: تبين من نتائج البحث أن هناك مجموعة منالمقترحات التي من شأنها رفع كفاءة تطبيق منظومة الخبز ومساعدتها في تحقيق أهدافها بصورة 
جيدة، كان من أهم هذه المقترحات تفعيل دور الجهات الرقابية علي جهات تتفيذ المنظومة خاصة المخابز ، كذلك عمل مكاتب وأرقام تليفونات معلنة لتلقي شكاوي المستهلكين وتلقي أفكارهم ومقترحاتهم والتفاعل معها لزيادة كفاءة عمل المنظومة، تفعيل دور مؤسسات المجتمع المدني في المنظومة من خلال إثراكها في رفع وعي المستهلكين وتوضيح حقوقهم وكيفية المطالبة بها وتوصيلها للمسئولين، تعديل فترات عمل المخابز بما يتتاسب مع ظروف المواطنين لتيسير حصولهم علي الخبز بصورة جيدة وتقليل الفاقد منه، ضرورة العمل علي تحسين جودة الرغيف ووزنه من خلال الرقابة الفعالة، وكذللك إلزام

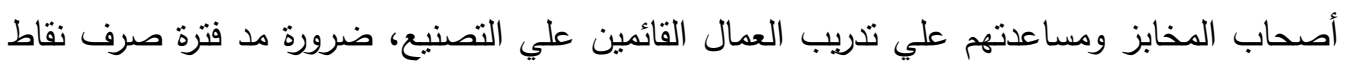

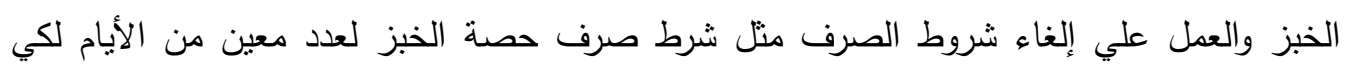

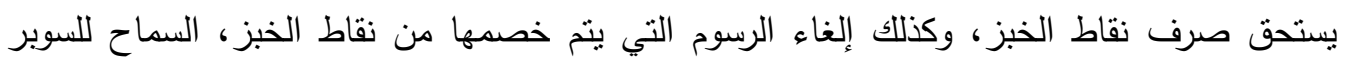

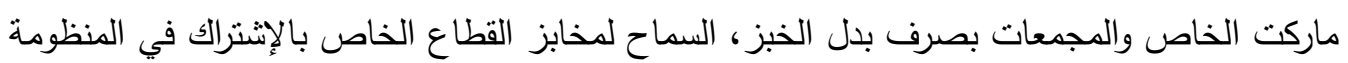
وتخصيص قروض إستثمارية لتشجيع الثباب علي عمل مخابز خاصة نتارك في المنظومة خاصة

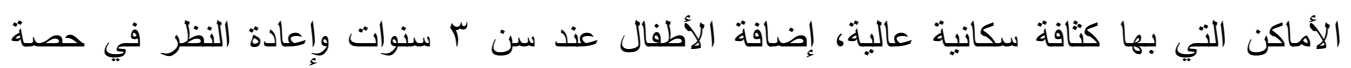

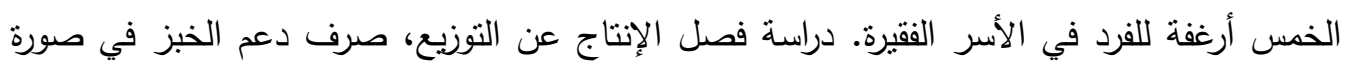

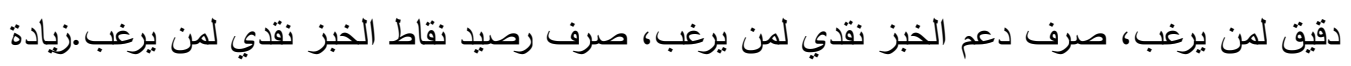

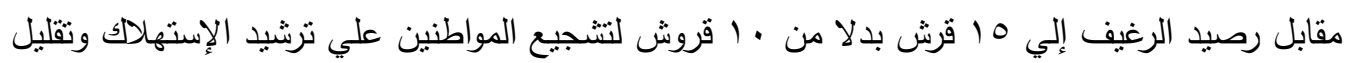
الفاقد من خبز المائدة.

أثر تطبيق منظومة الخبز الجديدة علي قطاع المخابز:يتتاول هذا الجزء من البحث تقيبم منظومة الخبز الجديدة بمحافظة بني سويف فيما يخص قطاع المخابز التي تعمل ضمن المنظومة وهي المني المخابز

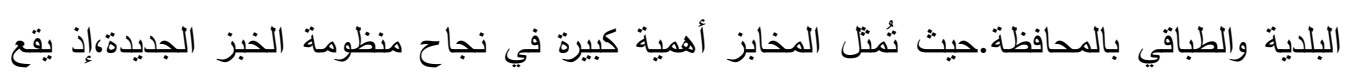
عليها عبء النهوض بجودة الرغيف، وكذلك التعامل مباشرة مع المستهلكين في ظل منظومة إلكترونية جديدة لم يعتاد عليها المواطن أو أصحاب المخابز من قبل.

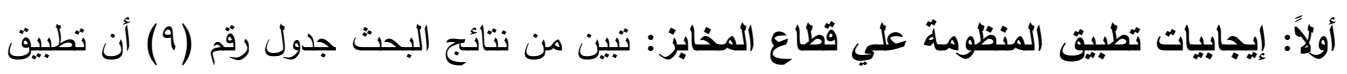

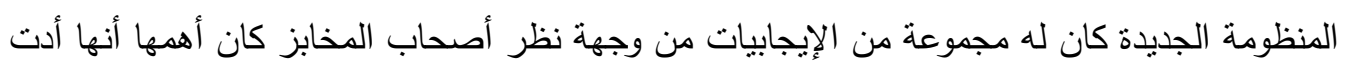

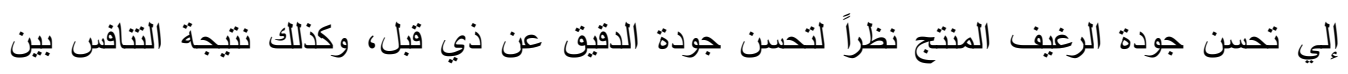

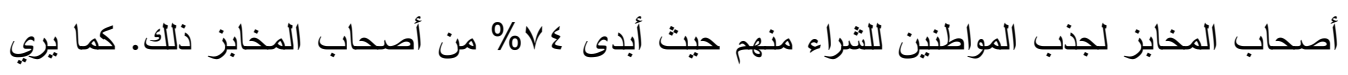

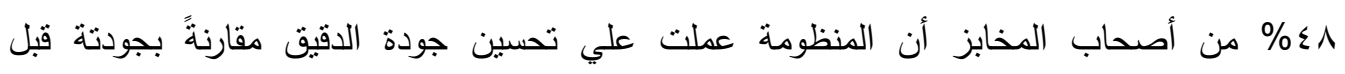

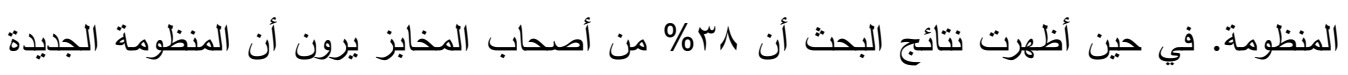

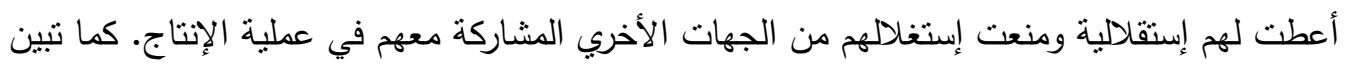

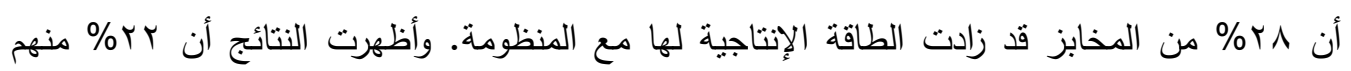

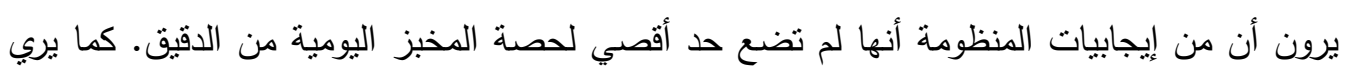

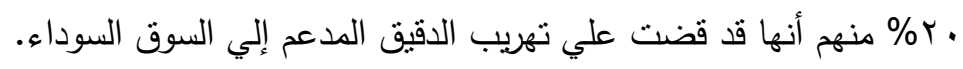
جدول رقم (^) : مقترحات تطوير وتحسين منظومة الخبز. 


\begin{tabular}{|c|c|c|}
\hline الأهمية & العدد & المقترح \\
\hline rra & 79 & تفعيل دور الجهات الرقابية على المنظومة خاصة رقابة التموين. \\
\hline r. r & 71 & عمل مكاتب وأرقام تليفونات معلنة لتلقي شكاوي المواطنين ومقترحاتهم. \\
\hline 19 & ov & تفعيل دور مؤسسات المجتمع المدني في رفع وعيالمواطنينومراقبة نطبيق المنظومة. \\
\hline IV.V & or & تعديل فترات عمل المخابز بما يتتاسب مع ظروف المواطنين. \\
\hline $10, \pi$ & $\leqslant 7$ & ضرورة العمل علي تحسين وزن وجودة الرغيف وإلزام أصحاب المخابز بذلك. \\
\hline $1 \leqslant$ & $\varepsilon r$ & مد فترة صرف بدل رصبد الخبز وإلغاء جميع شروط عدم الصرف. \\
\hline it & צ & إدخال السوبرماركت والمجمعات الخاصة في صرف بدل رصبد الخبز • . \\
\hline $1 \cdot 6$ & 山 & زيادة عدد الأفران داخل المنظومة والسماح للقطاع الخاص بالإنضمام لها. \\
\hline$\Lambda_{6} \mathrm{r}$ & ro & إضافة الأطفال عند سن r سنوات. \\
\hline 0 & 10 & صرف حصة فينو من خلال المنظومة خاصة في أيام المدارس. \\
\hline$\varepsilon, V$ & $1 \varepsilon$ & زيادة مقابل رصيد نقاط الرغيف إلي 10 قرش بدلا من · ا قروش. \\
\hline r.V & 11 & توزيع دعم الخبز فى صورة دقيق لمن يرغب. \\
\hline r.V & 11 & فصل الإنتاج عن التوزيع. \\
\hline r. & 1. & اعطاء دعم الخبز نقدى لمن يرغب على بطاقة التموين. \\
\hline r & 9 & صرف رصيد التوفير نقدى بدلا من السلع التموينية. \\
\hline $1 \ldots$ & r.. & إجمالي عينة البحث \\
\hline
\end{tabular}

المصدر : جمعت وحسبت من بيانات إستمارة الإستبيان.

ثانياً: المعوقات التي تواجه قطاع المخابز مع تطبيق المنظومة الجديدة:شُشير نتائج البحث جدول رقم

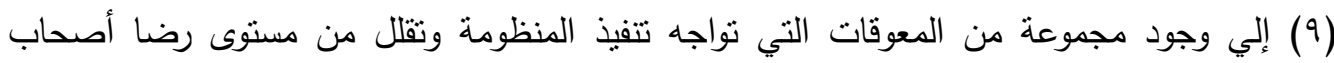

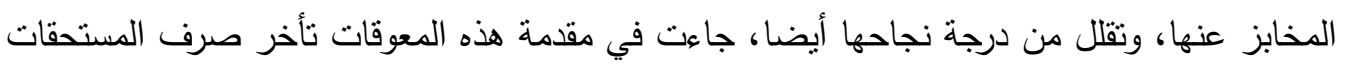

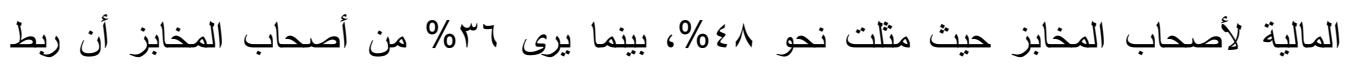
صرف المخبز لدقيق إستخلاص rی^\% ومن مطحن معين يضع قيودا أمامهم لتحسين جودة الخبز المنتج نظراً لإنخفاض جودة دقيق بعض المطاحن، في حين تسببت مشاكل ماكينة الصرف وكارت

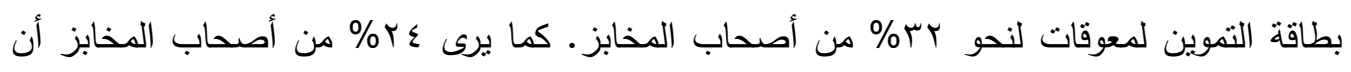

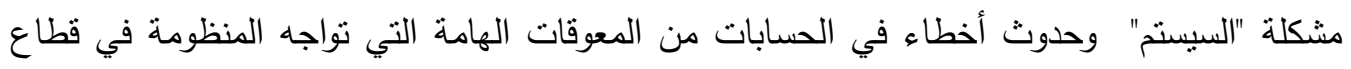

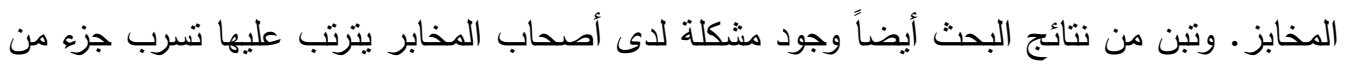

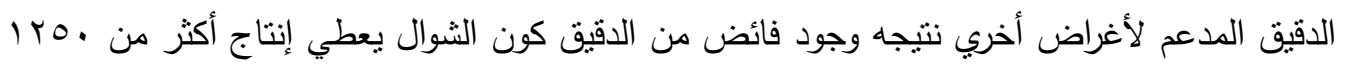

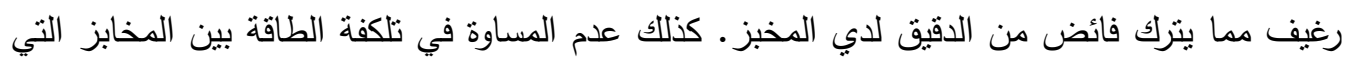

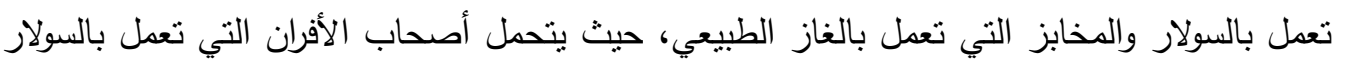
أضعاف تكلفة الطاقة للمخابز التي تعمل بالغاز الطبيعي، خاصة في أوقات الأزمات.

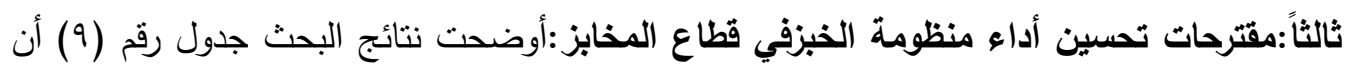

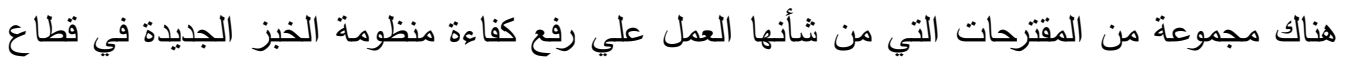

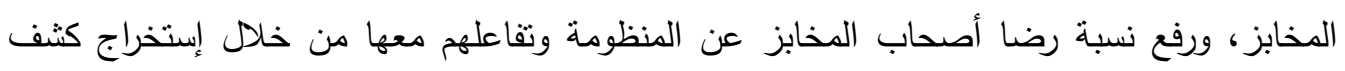
حساب يومي لهم في نهاية يوم العمل يوضح له حسابه خلال العمليات التي تمت طوال اليوم، يتبعها 
جدول رقم (9): إيجابيات ومعوقات المنظومة من وجهة نظر أصحاب المخابز.

\begin{tabular}{|c|c|c|}
\hline النسبية & عدد & البنود \\
\hline & & إيجابيات تطبيق المنظومة علي قطاع الهخابز : \\
\hline$V \varepsilon$ & rV & تحسن جودة الرغيف. \\
\hline «^ & $T \leq$ & تحسن جودة الدقيق. \\
\hline rA & 19 & عدم إستغلال أصحاب المخابز من الجهات الأخري المشاركة في العطلية الإنتاجية. \\
\hline rA & $1 \leqslant$ & زيادة الطاقة الإنتاجية للمخابز نتيجة زيادة كميات الدقيق اليومية. \\
\hline rr & 11 & عدم وجود حد أقصي لحصة المخبز من الدقيق. \\
\hline$r$. & 1. & القضاء علي تهريب الدقيق الددعم للسوق السوداء. \\
\hline & & معوقات تطبيق المنظومة بالنسبة لقطاع المخابز : \\
\hline$\leqslant \wedge$ & $r \varepsilon$ & تأخر صرف المستحقات المالية بصفة مستمرة. \\
\hline r4 & 11 & ربط صرف الدقيق للمخبز من إستخلاص معين (r^\%) ومطعن معين. \\
\hline rr & 17 & عيوب كلا من ماكينة الصرف والكارت المتكررة. \\
\hline$r \varepsilon$ & it & حدوث أخطاء في الحسابات بين المخابز والتموين ناتج عن مشاكل السيستم. \\
\hline rr & 11 & 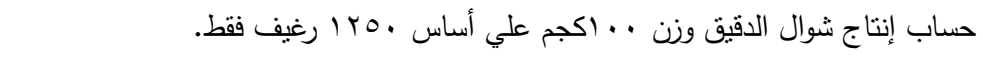 \\
\hline r. & 1. & عدم المساواة في أسعار الطاقة بين الأفران التي تعمل بالسولار والتي تعمل والغاز الطييعي. \\
\hline & & مقترحات تطوير ورفع جودة المنظومة في قطاع المخابز : \\
\hline v. & ro & عمل كثف حساب للمخبز في أخر كل يوم، وصرف المستحقات المالية في مواعيد ثابته. \\
\hline or & r & رفع كفاءة شركة سمارت، وفرض رقابة وجزاءات صارمة عليها لعدم تلاعبها باليبانات. \\
\hline$\varepsilon \wedge$ & $r \varepsilon$ & تطوير الثركة والإهتمام بصيانة الماكينة،وتوفير فني للأعطال الطارئه في وقت مناسب. \\
\hline$\varepsilon \varepsilon$ & r & 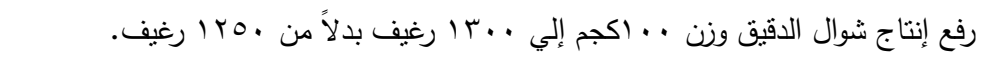 \\
\hline$\varepsilon r$ & r) & حرية شراء الدقيق من أي مطحن وأي نوع إستخلاص وذلك لتحسين جودة الخبز الناتج. \\
\hline rr & 17 & العمل علي تحسين جودة الدقيق الوارد من الدطاحن. \\
\hline rq & 15 & مساعدة المخابز في التحديث، وتدريب العاملين بها لتحسين جودة الخبز وتقليل الفاقد. \\
\hline
\end{tabular}

المصدر : جمعت وحسبت من بيانات إستمارة الإنتبيان.

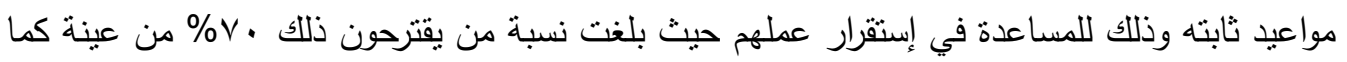
طالب نحو ro \% من أصحاب المخابز بمطالبة شركة سمارت برفع كفاءتها ورفع درجة الأمان للبيانات

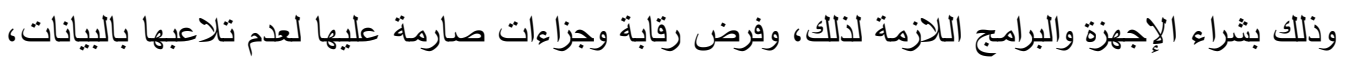

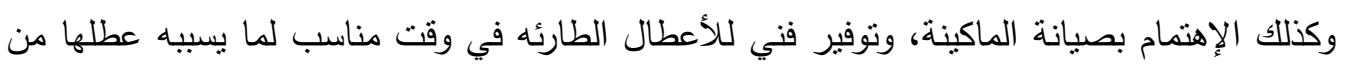

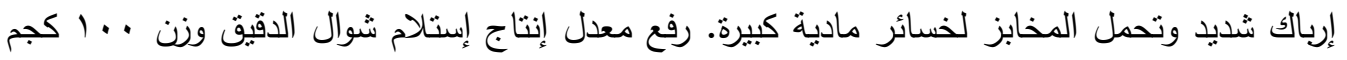

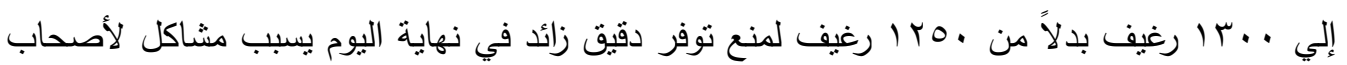

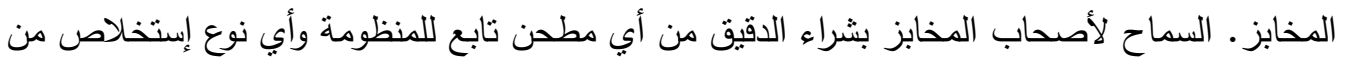
الاقيق وذلك لتحسين جودة الخبز الناتج. وكذلك مساعدة المخابز في التحديث، وتدريب العاملين بها 
أثر تطبيق منظومة الخبز الجديدة علي قطاع المطاحن:يتتاول هذا الجزء من البحث تقييم أثر تطبيق منظومة الخبز الجديدة علي قطاع المطاحن، حيث تبين من نتائج البحث أن نطبيق منظومة الخبز الجديدة علي المطاحن قد حقق مجموعة من الإيجابيات تمثلت في حصول صاحب المطحن علي الردة مقابل عملية الطحن مما عاد بالنفع المادي علي أصحاب المطاحن، زيادة الطاقة الإنتاجية الفعلية للمطاحن نتيجة زيادة الكميات الموردة إليها للطحن، تحسين جودة الدقيق الناتج، زيادة إيرادات

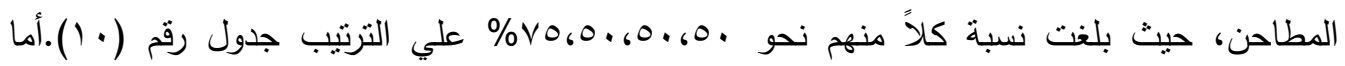
بالنسبة للمعوقات التي تقلل من نجاح المنظومة في قطاع المطاحن فهي عبارة عن أعطال شبكة الإنترنت، عدم إستقرار التوزيع اليومي للمطحن من الدقيق،إنخفاض جودة القمح أحياناً وإرتفاع نسبة أنسات

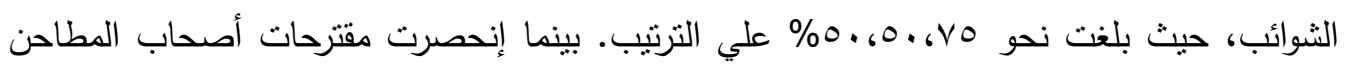
لتحسين جودة الطحن في العمل علي ثنات الكميات المطحونة يومياً، دفع مقابل الدقيق نقدي من هن هن

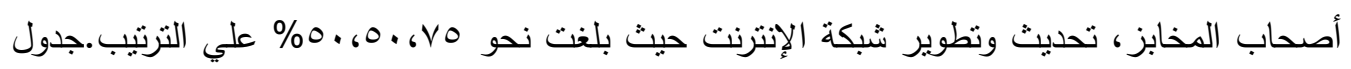

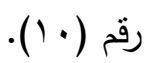

جدول رقم ( • 1): إيجابيات ومعوقات المنظومة لأصحاب المطاحن ومقترحاته.

\begin{tabular}{|c|c|c|c|}
\hline النسية & عدد & 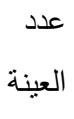 & 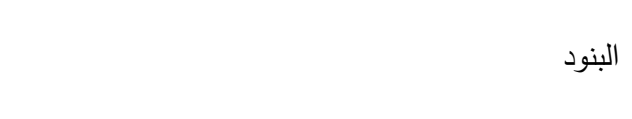 \\
\hline & & & 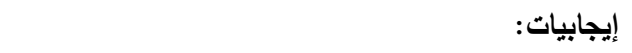 \\
\hline vo & r & & حصول صاحب المطحن علي الردة مقابل عملية الطحن. \\
\hline 0 . & r & $\varepsilon$ & زيادة الطاقة الإنتاجية الفعلية للمطاحن. \\
\hline o. & r & & ت تحسين جودة الدقيق. \\
\hline 0 . & r & & زيادة إيرادات المطاحن. \\
\hline & & & معوقات: - معات \\
\hline vo & r & $\varepsilon$ & أعطال شبكة الإنترنت. \\
\hline 0 . & r & & عدم إسنتقرار التوزيع اليومي من الدقيق. \\
\hline o. & r & & إنخفاض جودة القمح أحياناً وارتفاع نسبة الثوائب. \\
\hline & & & 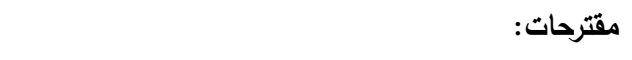 \\
\hline vo & r & $\varepsilon$ & تحديث وتطوير شبكة الإنترنت. \\
\hline o. & r & & العمل علي ثبات كميات القمح المطحونة يومياً. \\
\hline 0 . & r & & دفع مقابل الدقيق نقدي من أصحاب المخابز . \\
\hline
\end{tabular}

المصدر : جمعت وحسبت من بيانات إستمارة الإستبيان. الملخص والتوصيات

تبين من نتائج البحث أن: منظومة الخبز الجديدة بدأ تتفيذها في محافظة بني سويف في بداية شهر

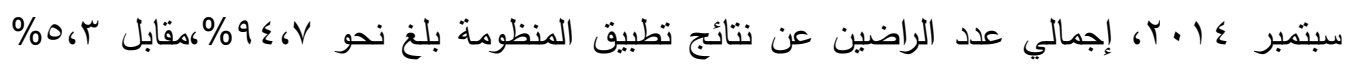

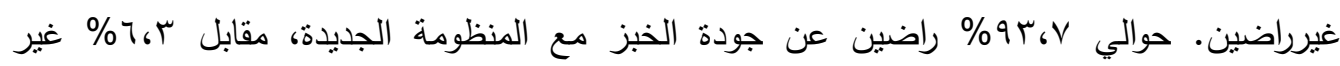

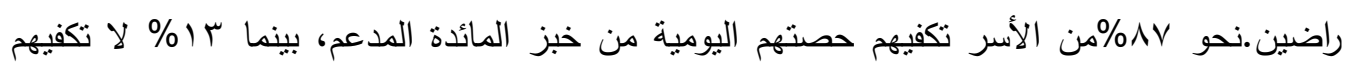
الحصة اليومية.نحو VV\% من الأسر إنخفض منوسط إنفاقهم الثهري علي شراء خبز المائدة، وظل 


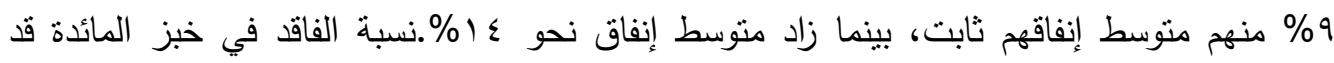

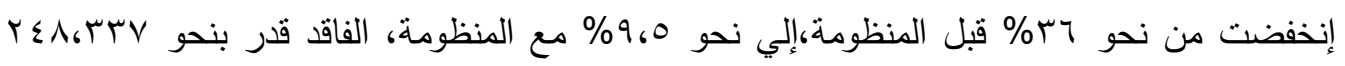

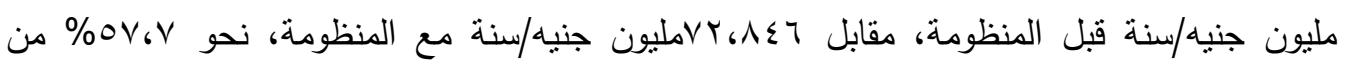

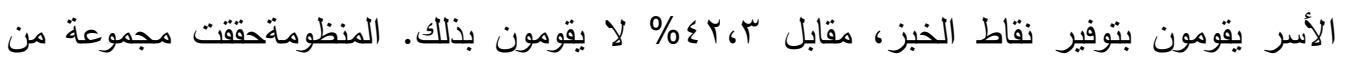

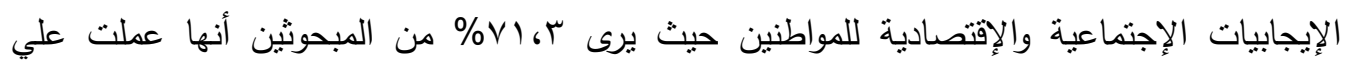

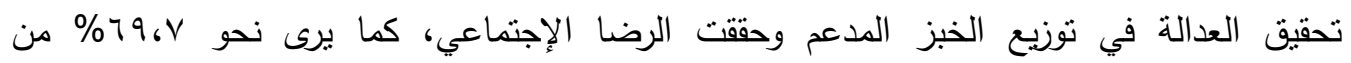

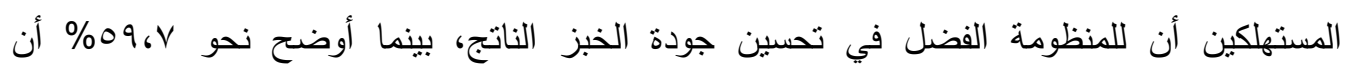
المنظومة عملت علي تيسير وسهولة حصول المواطنين علي حصنهم اليوميه من الخبز وإختفاء طوابير

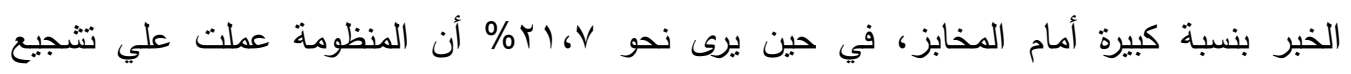

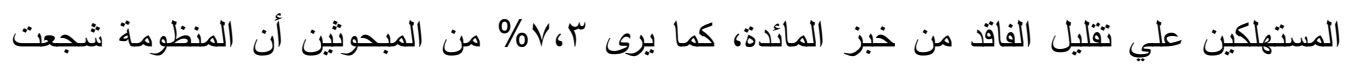

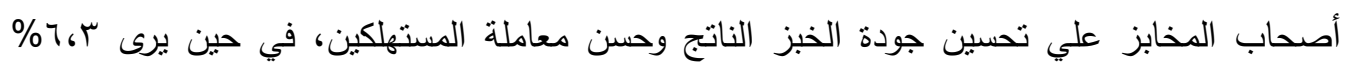
منهم أن المنظومة الجديدة عملت علي القضاء علي تهريب الدقيق المدعم وبيعه في السوق السوداء.

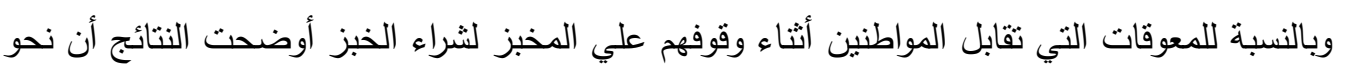

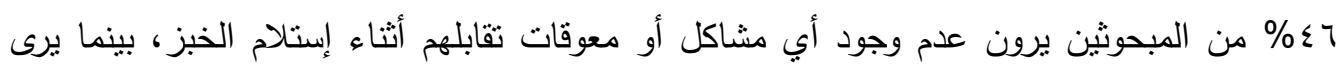

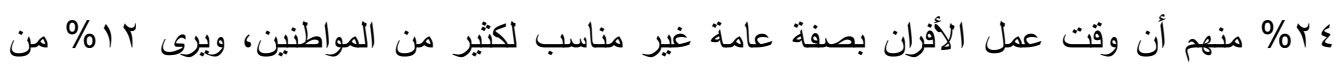

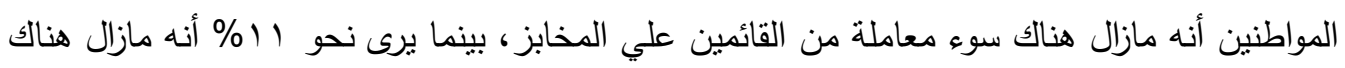

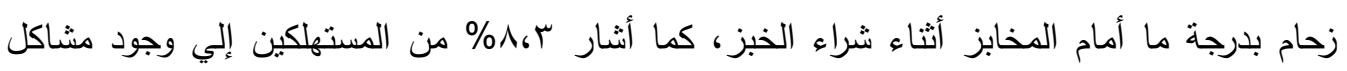

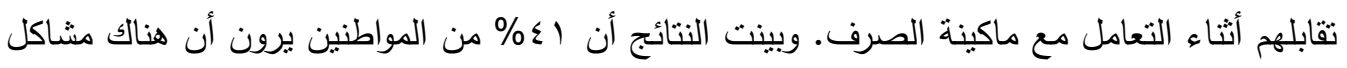

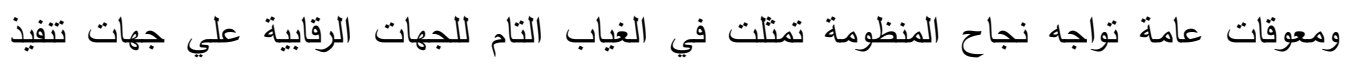

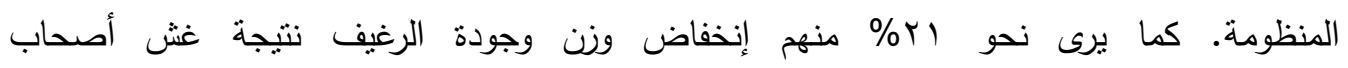

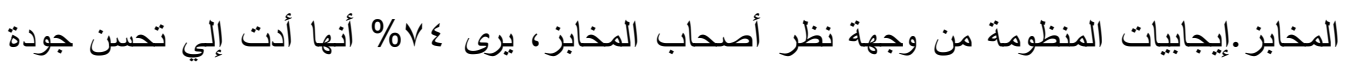

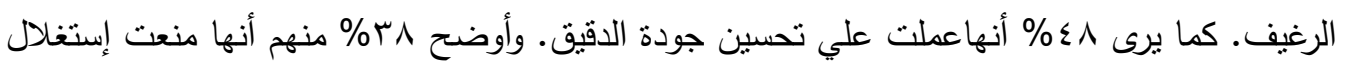

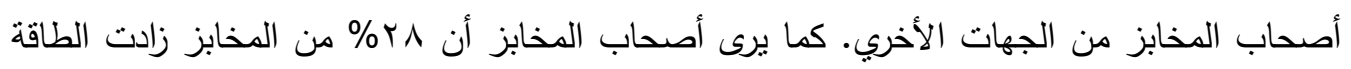

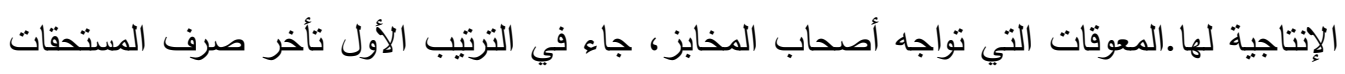

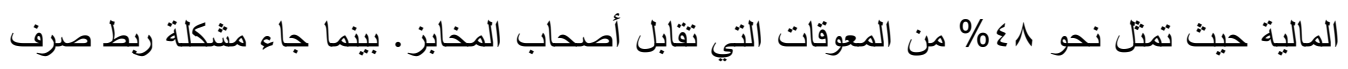

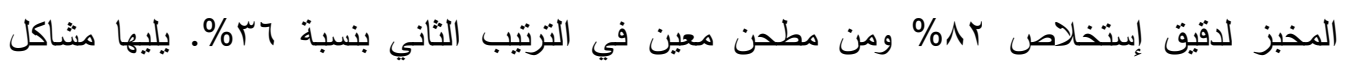

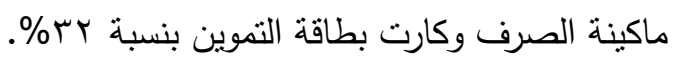

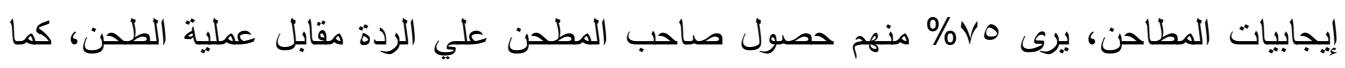
برى •0\% زيادة الطاقة الإنتاجية الفعلية للمطاحن، تحسين جودة الدقيق الناتج، زيادة إيرادات

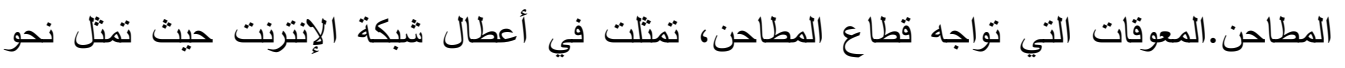

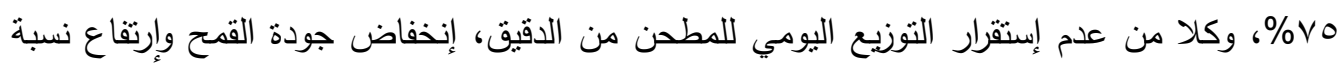
الثوائب بنسبة .0\% كل وحل عنها. 
تفعيل دور الجهات الرقابية بدرجة اكبر من المتبع الان علي جهات تتفيذ المنظومة خاصة المخابز، عمل مكاتب وأرقام تليفونات معلنه لتلقي شكاوي المواطنين وتلقي أفكارهم ومقترحاتهم، تفعيل دور مؤسسات الهنمع المدني في المنظومة لرفع وعي المستهلكين، تعديل فترات عمل المخابز بما يتتاسب

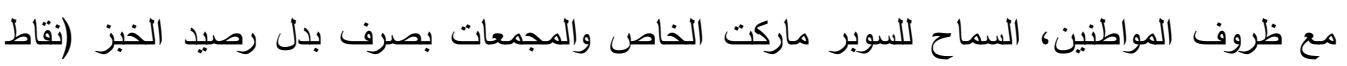
الخبز)، إضافة الأطفال عند سن آسنوات وإعادة النظر في حصة الخمس أرغفة للفرد في الأسر

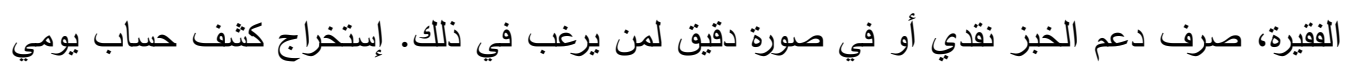

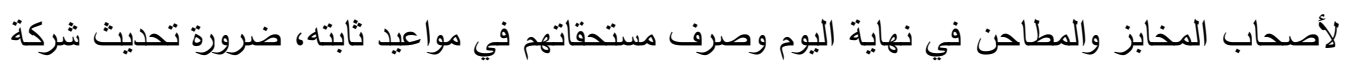

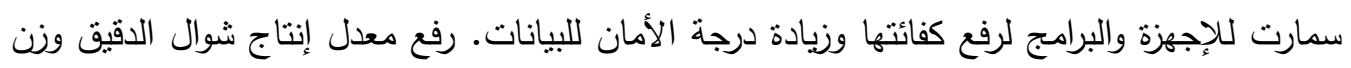

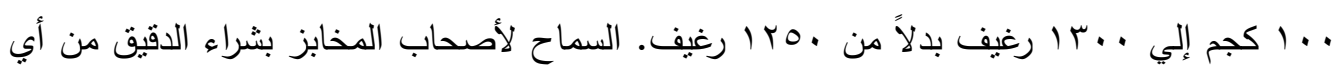
مطحن تابع للمنظومة وأي نوع إستخلاص من الدقيق لتحسين جودة الخبز الناتج. المراجع

ا. الجهاز المركزي للتعبئة العامة والإحصاء، شبكة مركز التوثيق والمعلومات.

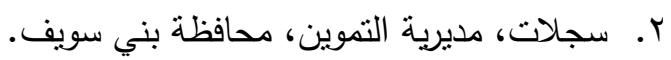

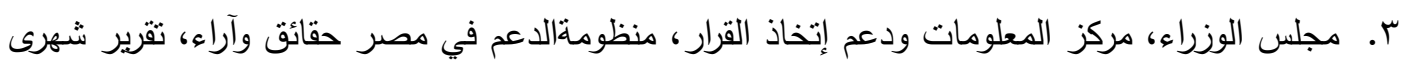

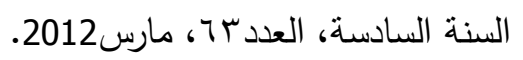
ع. محمد عبد الغني رمضان(دكتور) وأخرون، مؤثر الغذاء المصري، مجلس الوزراء، مركز المعلومات

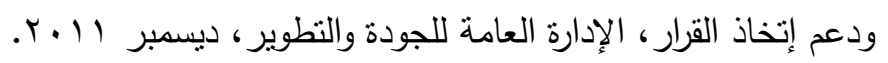

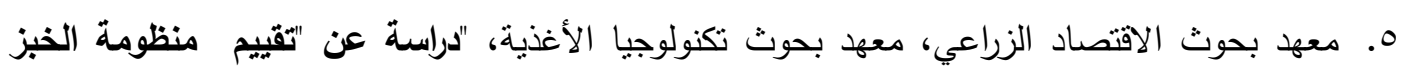
لإنتاج خبز مدعم r^\% "، بـ المؤتمر الثالث لتكنولوجيا صناعة الحبوب (منظومة الخبز)، مركز القاهرة

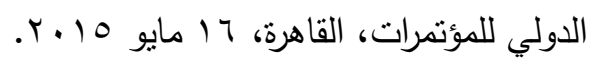




\title{
EVALUATION OF NEW SYSTEM OF BREAD IN BENI SUEF GOVERNORATE
}

\author{
HUSSEIN M. A. ROSTOM and ABDELAZYEM S. A. ABDELLATIF
}

\author{
Food Technology Research Institute, ARC, Giza, Egypt
}

(Manuscript received 23 June 2015)

\begin{abstract}
$\mathrm{R}$ esults showed that, the new system of bread subsidy was carried out at Beni suef governorate in Sept. 2014, Those families who agreed this system reached $94.7 \%, 93.7$ of them are satisfied by the quality of the bread under this system, $27 \%$ of them decreased their monthly expenditure on buying beard, Loss in bread decreased from $36 \%$ before applying this system to $9.5 \%$ after applying it. Value of loss decreased from 248.337 million pound/year to 72.846 million pound/year. Also results showed that $57.7 \%$ of families save bread points. The obtained results also showed that $71.3 \%$ of the sample under study showed that there are social justice in distribution of bread $69.7 \%$ of consumers said that, they can get the bread easier. Also, $46 \%$ of consumers don't find any problems in applying this system in spite of absence of any control authority, on the other hand, $24 \%$ of the consumers said that the time of work for bakeries is not suitable, $12 \%$ of consumers find bad manner in front of the bakeries from their owners, $11 \%$ suffer from crowdness in front of the bakeries and $8.3 \%$ of the consumers find problems during operating the electronic card. As for bakery owners, $74 \%$ of them said that this system improved the quality of the beard, $48 \%$ of them said that this system improved the quality of flour, and $28 \%$ of them said that the production capacity increased due to applying this system, meanwhile $48 \%$ of them claiming the delaying of financial duties $36 \%$ claimed connecting getting flour extraction $82 \%$ by certain millers, $32 \%$ had claimed the electronic card.

As for the millers $75 \%$ of the owners of millers said that getting the bra in front of milling process is good, also $50 \%$ of them said that this system resulted, increasing production capacity, improving flour capacity and increasing of the process of milling. On the other side, $75 \%$ of them claimed the disorder in the net, and the instability in the daily distribution of flour, and the bad quality of wheat in some cases and the high \% of impurities.
\end{abstract}

\section{Recommendations:}

The study recommended:

- Strengthening the control authorities controlling this system specially in case of bakeries.

- Improving the awareness of consumer.

- Extending the period of exchange bread pointes, and allowing the exchange bread pointes for supermarkets and other sites.

- Making daily account for the owners of bakeries.

- Taking in consideration adding children of 4 years old to this system.

- Increasing production rate for bags $100 \mathrm{~kg}$ to 1300 loaf.

- Allowing the owners of bakeries to buy flour from any miller followed this system and buying any type of extraction. 